\begin{tabular}{|c|c|c|}
\hline Case Reports in & \multicolumn{2}{|c|}{ Case Rep Gastroenterol 2020;14:197-205 } \\
\hline Gastroenterology & $\begin{array}{l}\text { DOI: 10.1159/000506926 } \\
\text { Published online: April 21, } 2020\end{array}$ & $\begin{array}{l}\text { (c) } 2020 \text { The Author(s) } \\
\text { Published by S. Karger AG, Basel } \\
\text { www.karger.com/crg }\end{array}$ \\
\hline & $\begin{array}{l}\text { This article is licensed under } \\
\text { International License (CC BY-N } \\
\text { Usage and distribution for comm }\end{array}$ & $\begin{array}{l}\text { nons Attribution-NonCommercial } 4.0 \\
\text { ger.com/Services/OpenAccessLicense). } \\
\text { uires written permission. }\end{array}$ \\
\hline
\end{tabular}

\title{
Rapidly Growing Desmoid-Type Fibromatosis of the Mesentery of the Small Intestine after Distal Gastrectomy for Gastric Cancer
}

\author{
Ryota Koyama Yoshiaki Maeda Nozomi Minagawa Toshiki Shinohara \\ Department of Gastrointestinal Surgery, Hokkaido Cancer Center, Sapporo, Japan
}

\section{Keywords}

Chylous ascites · Gastric cancer · Total gastrectomy · Roux-en-Y reconstruction · Internal hernia $\cdot$ Mesenteric defect $\cdot$ Laparoscopic surgery

\begin{abstract}
We report the case of a 55-year-old man with a surgical history of distal gastrectomy with Roux-en-Y reconstruction performed 3 years prior to the present episode. During the followup, a newly developed, rapidly growing intraabdominal mass was detected in the mesentery of the small intestine. Although the patient had been asymptomatic, surgical resection was planned with the suspicion of malignancy, especially lymph node recurrence of the gastric cancer, owing to its rapid growth. Laparotomy showed that the tumor was located in the mesentery of the small intestine near the Roux-en-Y limb, and due to the involvement of the feeding vessels to the Roux-en-Y limb, the anastomotic site was resected en bloc with the tumor, and the whole Roux-en-Y limb was reconstructed. The histopathological finding was compatible with desmoid-type fibromatosis of the mesentery of the small intestine. Here we report our case and discuss the previously reported literature, especially related to gastric cancer.
\end{abstract}




\section{Case Reports in Gastroenterology}

Case Rep Gastroenterol 2020;14:197-205

DOI: $10.1159 / 000506926$

c) 2020 The Author(s). Published by S. Karger AG, Basel www.karger.com/crg

Koyama et al.: Desmoid-Type Fibromatosis of the Mesentery of the Small Intestine

\section{Introduction}

Desmoid-type fibromatosis (DF) is a rare slow-growing soft tissue tumor that shows local invasiveness without the ability to metastasize [1]. Herein, we report a case of DF developed from the mesentery of the small intestine neighboring the Roux-en-Y limb in a patient who had a surgical history of distal gastrectomy with Roux-en-Y reconstruction. Roux-en-Y reconstruction is a method of gastrointestinal reconstruction by gastrojejunostomy and creates a Roux-en-Y limb, which is a jejunojejunal anastomosis to establish intestinal continuity. We successfully resected the tumor and neighboring Roux-en-Y limb en bloc and reconstructed the whole Roux-en-Y limb. DF following gastrectomy for gastric cancer is very rare, and few cases have been reported thus far. We report our case with a review of the relevant literature.

\section{Case Presentation}

A 55-year-old man with a previous surgical history of distal gastrectomy with antecolic Roux-en Y reconstruction performed 3 years previously for gastric cancer (tub2, T1, N0, M0, pStage IA) presented with a rapidly growing intraabdominal mass that had developed during the postoperative course. The patient had not undergone adjuvant chemotherapy and had no medical or surgical history other than that of gastric cancer.

On admission, his height was $167 \mathrm{~cm}$, weight was $49 \mathrm{~kg}$, blood pressure was 118/73 mm $\mathrm{Hg}$, heart rate was 67 beats $/ \mathrm{min}$, and body temperature was $36.6^{\circ} \mathrm{C}$. The abdomen was soft and flat with a midline incision scar. A mobile, elastic, hard mass was palpable on the left side of the abdomen. His complete blood count and serum chemistry results were normal, and all of the examined tumor markers (carbohydrate antigen 19-9, carcinoembryonic antigen, $\alpha$-fetoprotein, neuron-specific enolase, cytokeratin 19 fragment, and soluble interleukin-2 receptor) were within their normal limits.

Abdominal contrast-enhanced computed tomography (CT) initially detected a newly appearing small mass measuring $14 \mathrm{~mm}$, neighboring the Roux-en-Y limb anastomosis without invasion into the small bowel 22 months previously (although this was confirmed only via retrospective observation). The mass had increased in size from $33 \mathrm{~mm}$ ( 6 months before) to $82 \mathrm{~mm}$ at the time of the operation (Fig. 1). On the preoperative CT, the tumor was $82 \times 75$ $\mathrm{mm}$ in size, and it appeared to originate from the mesentery of the small intestine. We determined the most likely differential diagnosis of gastrointestinal stromal tumor and lymph node recurrence of the gastric cancer, and DF was not included in the list. ${ }^{18} \mathrm{~F}-2$-fluoro-2-deoxyglucose positron emission tomography (PET) revealed a heterogeneously enhanced uptake on the lesion $\left(\mathrm{SUV}_{\max }=4.40\right)$ in the lower abdomen. The mobility of the tumor from the previous CTs also supported the origin of the mesentery. Apart from this, there were no significant findings that indicated metastasis or any other lesions (Fig. 2). Biopsy was considered because chemotherapy, not surgery, may be needed in case of recurrence of the gastric cancer. However, this strategy was abandoned owing to the lack of a suitable route for a percutaneous or endoscopy-assisted approach.

Overall, we suspected that a malignant lesion was located in the mesentery near the Rouxen-Y limb that was responsible for its rapid growth. There was no other lesion elsewhere; therefore, we decided to perform resection for both diagnosis and treatment.

Laparotomy showed that the tumor was located in the mesentery of the small intestine near the Roux-en-Y limb. The feeding vessels for the Roux-en-Y limb anastomotic site were partly involved by the tumor; therefore, the anastomotic site was resected en bloc with the 
tumor, and the whole Roux-en-Y limb was reconstructed with functional end-to-end anastomosis using a linear stapler. No intraperitoneal dissemination or distant metastasis was observed during the surgery.

Macroscopically, the resected specimen was a $10 \times 9 \times 8 \mathrm{~cm}$-sized solid lesion with no necrosis or bleeding (Fig. 3). No exposure to the mucosa of the adjacent small intestine was observed, indicating its origin in the mesentery. Histopathological findings revealed that the tumor was located in the mesentery of the small intestine, and spindle-shaped cells resembling fibroblasts or myofibroblasts proliferated sparsely with intervening collagen fibers. Invasive proliferation into the surrounding fat tissue was observed in the marginal area of the tumor (Fig. 4). The immunohistochemistry results were negative for desmin, $\alpha$-smooth muscle actin, CD34, and c-kit. Moreover, positivity for the nuclear accumulation of $\beta$-catenin was observed (Fig. 4). In accordance with our findings, DF of the mesentery was diagnosed.

The postoperative course was uneventful, and the patient was discharged on postoperative day 13. At the time of writing of this report, the patient was free from recurrence with no adjuvant treatment and was being carefully followed up with CT.

\section{Discussion}

DF, also called desmoid tumor, deep fibromatosis, or aggressive fibromatosis, is a slowgrowing soft tissue tumor that is clinically characterized as locally invasive but without the potential to metastasize [1]. Most cases of DF occur sporadically; however, $5 \%$ are observed in patients with familial adenomatous polyposis (FAP), an autosomal dominant inherited cancer predisposition syndrome caused by germline mutation of the adenomatous polyposis coli (APC) gene [2-4].

DF may arise at any anatomical site; however, about $10 \%$ of sporadic DF affects intraabdominal organs $[5,6]$. It usually occurs in the mesentery, retroperitoneum, or omentum; however, internal organs, such as the pancreas [7] and the stomach [8], are also reported to be involved. Intraabdominal DF shows a worse prognosis owing to the proximity to vital organs, resulting in grave consequences in cases of invasions, such as aneurysm formation [9] and bowel obstruction [10].

The complete etiology of DF remains unclear; however, the activating mutation of CTNNB1 (which encodes $\beta$-catenin) is observed in about $85-90 \%$ of DF patients, leading to nuclear accumulation of $\beta$-catenin [11]. Both loss of APC in FAP patients and activation of CTNNB1 mutation lead to the continuous stimulation of the Wnt/ $\beta$-catenin pathway [12]; this contributes to aberrant cell proliferation. It is noteworthy that the mutation of $\beta$-catenin and APC is mutually exclusive; hence, non-FAP DF patients may be recommended for FAP screening [13].

Furthermore, the upregulation of estrogen aggravates the disease, which explains the sex preference for females, especially during pregnancy and before menopause, and the direct effectiveness of tamoxifen, an inhibitor of estrogen, in DF [14].

It is noteworthy that a history of trauma before the surgery is a validated risk factor [15]. Carothers et al. [16] found that DF is caused by acquisition of a proliferative benefit for mesenchymal stem cells in a wound healing setting by continuous stimulation of the Wnt signaling pathway. Moreover, the histology is almost indistinguishable from that of hypertrophic scars or keloids of the skin. The analogy is also applicable, such as high rates of recurrence after resection, predilection for younger females, and continuous activation of the Wnt signaling 
pathway $[17,18]$. Therefore, further research on the analogy between these conditions is warranted.

The treatment for DF is shifting toward a nonsurgical approach (the "wait-and-watch" approach) for nonprogressing and asymptomatic patients, because of its high recurrence rate after radical resection $[19,20]$. However, close follow-up is required for DF owing to the variable and unpredictable natural history; on DF progression, surgical resection is considered.

For surgical resection, local recurrence is the center of interest for its nonnegligibly high rate. Since the tumor has no capsule and due to the infiltrative invasion at the boundaries, the intraoperative determination of $\mathrm{R} 0$ resection remains challenging. A study on the challenge faced by operating surgeons that included 426 patients showed that R0 and R1 resection had no significant impact on progression-free survival. Further, recurrent DF is in itself a risk factor for recurrence [21]. However, in a study of 189 patients who underwent surgery for DF, R0 resection showed a significantly lower recurrence rate than R1 resection (27 vs. 54\%; $p=$ 0.03 ] [22]. Thus, when the surgery is planned, surgeons should make their best effort to secure a clear margin from the tumor.

DF after gastrectomy for gastric cancer has been reported by a few authors [23-27]. This condition is very challenging for clinicians because the treatment strategy differs greatly for $\mathrm{DF}$ and cancer recurrence. Most patients were presumptively diagnosed with gastric cancer recurrence. This indicates a high prevalence of false diagnosis of DF, given that no effort to obtain the specimen is made when recurrence is diagnosed on imaging studies. The lesson learnt from the literature and the present case is that when there is a novel lesion suspected to indicate lymph node recurrence with no apparent metastasis elsewhere during the postgastrectomy period, resection is recommended for both diagnosis and treatment, because DF is more manageable if there is no invasion into the vital organs and completely lacks metastatic capability.

\section{Statement of Ethics}

Written informed consent was obtained from the patient for publication of this case report and any accompanying images.

\section{Disclosure Statement}

The authors have no conflicts of interest to declare.

\section{Funding Sources}

This work received no funding.

\section{Author Contributions}

R.K. is the primary investigator and contributed to conceptualization, data collection, and drafting of the manuscript. All authors have read and approved this manuscript for publication. 


\section{References}

1 Chaudhary P. Mesenteric fibromatosis. Int J Colorectal Dis. 2014 Dec;29(12):1445-51.

2 Quintini C, Ward G, Shatnawei A, Xhaja X, Hashimoto K, Steiger E, et al. Mortality of intra-abdominal desmoid tumors in patients with familial adenomatous polyposis: a single center review of 154 patients. Ann Surg. 2012 Mar;255(3):511-6.

3 Nieuwenhuis MH, Casparie M, Mathus-Vliegen LM, Dekkers OM, Hogendoorn PC, Vasen HF. A nation-wide study comparing sporadic and familial adenomatous polyposis-related desmoid-type fibromatoses. Int J Cancer. 2011 Jul;129(1):256-61.

4 Groen EJ, Roos A, Muntinghe FL, Enting RH, de Vries J, Kleibeuker JH, et al. Extra-intestinal manifestations of familial adenomatous polyposis. Ann Surg Oncol. 2008 Sep;15(9):2439-50.

5 Ogawa N, Iseki $\mathrm{H}$, Tsunozaki H, Hayashi M, Baba H, Matsuyama T, et al. Intra-abdominal desmoid tumor difficult to distinguish from a gastrointestinal stromal tumor: report of two cases. Surg Today. 2014 Nov;44(11):2174-9.

6 Gupta S, Ray U, Chatterjee S, Kumar S, Satapathy A, Chatterjee S, et al. Sporadic intra-abdominal desmoid: a rare presentation as a hepatic mass. Case Rep Pathol. 2012;2012:245671.

7 Słowik-Moczydłowska Ż, Rogulski R, Piotrowska A, Małdyk J, Kluge P, Kamiński A. Desmoid tumor of the pancreas: a case report. J Med Case Reports. 2015 May;9(1):104.

8 Date K, Shima Y, Okabayashi T, Iwata J, Sumiyoshi T, Kozuki A. Desmoid tumor of the stomach. Endoscopy. 2015;47 Suppl 1 UCTN:E242-3.

9 Tatsumi K, Bundock EA. Splenic Artery Aneurysm Invaded by Desmoid-Type Fibromatosis. Am J Forensic Med Pathol. 2015 Sep;36(3):202-4.

10 Aggarwal G, Shukla S, Maheshwari A, Mathur R. Desmoid tumour: a rare etiology of intestinal obstruction. Pan Afr Med J. 2015 Oct;22:158.

11 Mullen JT, Delaney TF, Kobayashi WK, Szymonifka J, Yeap BY, Chen YL, et al. Desmoid tumor: analysis of prognostic factors and outcomes in a surgical series. Ann Surg Oncol. 2012 Dec;19(13):4028-35.

12 Timbergen MJ, Smits R, Grünhagen DJ, Verhoef C, Sleijfer S, Wiemer EA. Activated Signaling Pathways and Targeted Therapies in Desmoid-Type Fibromatosis: A Literature Review. Front Oncol. 2019 May;9:397.

13 Wang WL, Nero C, Pappo A, Lev D, Lazar AJ, López-Terrada D. CTNNB1 genotyping and APC screening in pediatric desmoid tumors: a proposed algorithm. Pediatr Dev Pathol. 2012 Sep-Oct;15(5):361-7.

14 Fiore M, Colombo C, Radaelli S, Callegaro D, Palassini E, Barisella M, et al. Hormonal manipulation with toremifene in sporadic desmoid-type fibromatosis. Eur J Cancer. 2015 Dec;51(18):2800-7.

15 Tanaka K, Yoshikawa R, Yanagi H, Gega M, Fujiwara Y, Hashimoto-Tamaoki T, et al. Regression of sporadic intra-abdominal desmoid tumour following administration of non-steroidal anti-inflammatory drug. World J Surg Oncol. 2008 Feb;6(1):17.

16 Carothers AM, Rizvi H, Hasson RM, Heit YI, Davids JS, Bertagnolli MM, et al. Mesenchymal stromal cell mutations and wound healing contribute to the etiology of desmoid tumors. Cancer Res. 2012 Jan;72(1):346-55.

17 Tsai CH, Ogawa R. Keloid research: current status and future directions. Scars Burn Heal. 2019 Aug;5:2059513119868659.

18 Igota S, Tosa M, Murakami M, Egawa S, Shimizu H, Hyakusoku H, et al. Identification and characterization of Wnt signaling pathway in keloid pathogenesis. Int J Med Sci. 2013;10(4):344-54.

19 Kasper B, Baumgarten C, Garcia J, Bonvalot S, Haas R, Haller F, et al.; Desmoid Working Group. An update on the management of sporadic desmoid-type fibromatosis: a European Consensus Initiative between Sarcoma PAtients EuroNet (SPAEN) and European Organization for Research and Treatment of Cancer (EORTC)/Soft Tissue and Bone Sarcoma Group (STBSG). Ann Oncol. 2017 Oct;28(10):2399-408.

20 Smith AJ, Lewis JJ, Merchant NB, Leung DH, Woodruff JM, Brennan MF. Surgical management of intraabdominal desmoid tumours. Br J Surg. 2000 May;87(5):608-13.

21 Salas S, Dufresne A, Bui B, Blay JY, Terrier P, Ranchere-Vince D, et al. Prognostic factors influencing progression-free survival determined from a series of sporadic desmoid tumors: a wait-and-see policy according to tumor presentation. J Clin Oncol. 2011 Sep;29(26):3553-8.

22 Ballo MT, Zagars GK, Pollack A, Pisters PW, Pollack RA. Desmoid tumor: prognostic factors and outcome after surgery, radiation therapy, or combined surgery and radiation therapy. J Clin Oncol. 1999 Jan;17(1):158-67.

23 Komatsu S, Ichikawa D, Kurioka H, Koide K, Ueshima Y, Shioaki Y, et al. Intra-abdominal desmoid tumor mimicking lymph node recurrence after gastrectomy for gastric cancer. J Gastroenterol Hepatol. 2006 Jul;21(7):1224-6.

24 Tamura K, Tani M, Kinoshita H, Yamaue H. Mesenteric desmoid tumor of the interposed jejunal pouch after total gastrectomy. World J Surg Oncol. 2006 Jun;4(1):27.

25 Okamura A, Takahashi T, Saikawa Y, Mayanagi S, Fukuda K, Nakamura R, et al. Intra-abdominal desmoid tumor mimicking gastric cancer recurrence: a case report. World J Surg Oncol. 2014 May;12(1):146.

26 Kim PS, Han DS, Han HS, Bang HY. Intra-abdominal fibromatosis after gastrectomy for gastric cancer. Ann Surg Treat Res. 2014 Dec;87(6):331-5. 


\section{Case Reports in Gastroenterology}

\begin{tabular}{l|l}
\hline Case Rep Gastroenterol 2020;14:197-205 \\
\hline DOI: 10.1159/000506926 & $\begin{array}{l}\text { @ 2020 The Author(s). Published by S. Karger AG, Basel } \\
\text { www.karger.com/crg }\end{array}$ \\
\hline
\end{tabular}

Koyama et al.: Desmoid-Type Fibromatosis of the Mesentery of the Small Intestine

27 Yamamoto R, Mokuno Y, Matsubara H, Kaneko H, lyomasa S. Multiple mesenteric desmoid tumors after gastrectomy for gastric cancer: a case report and literature review. Int J Surg Case Rep. 2018;50:50-5.
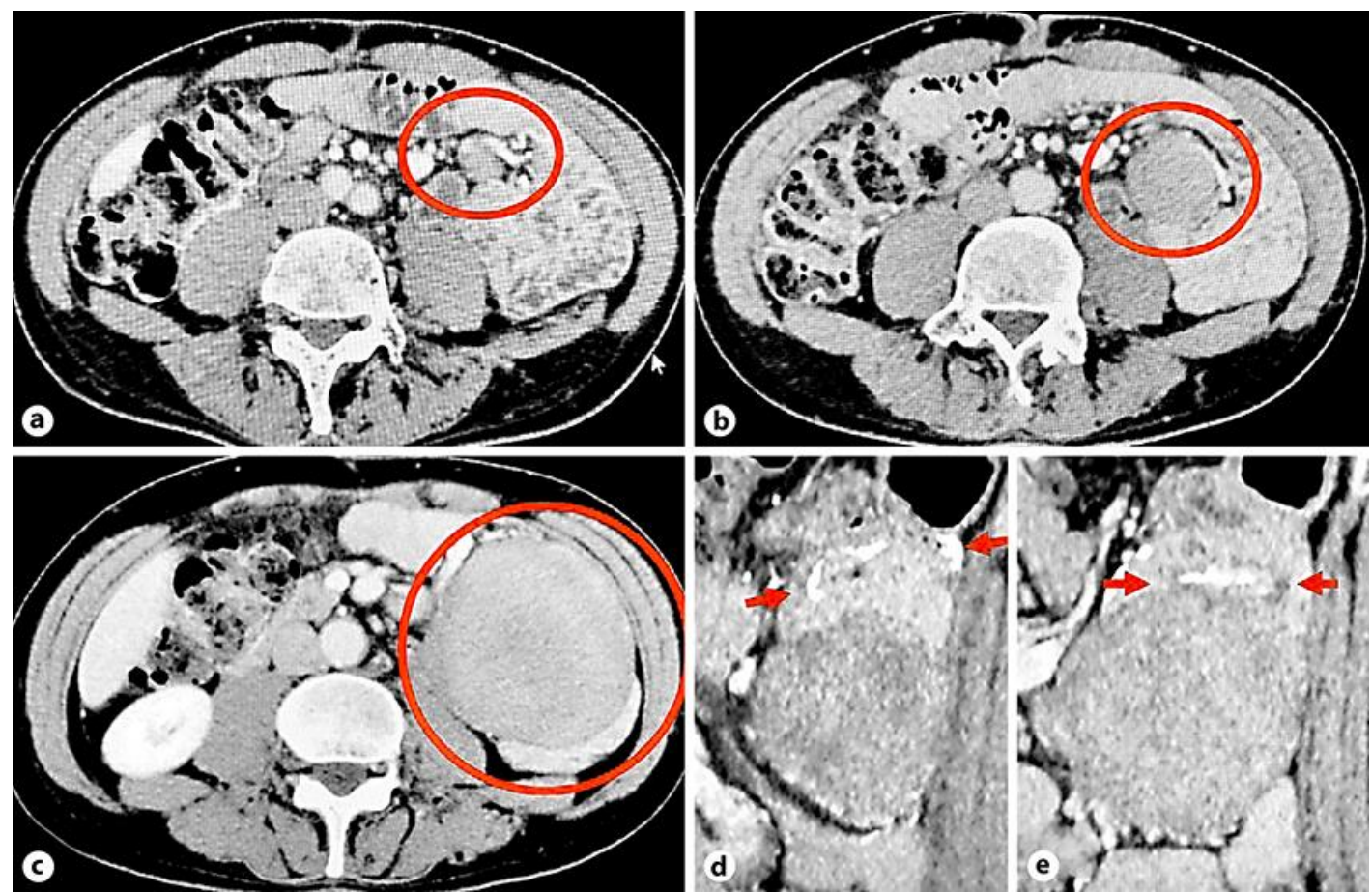

Fig. 1. Computed tomography (CT) images. a A new, 14-mm mass appeared adjacent to the Roux-en-Y limb without invasion into the small bowel (22 months ago; circle: tumor). $\mathbf{b}$ The tumor increased in size to 33 mm 6 months ago (circle: tumor). c-e Preoperative CT showed a heterogeneously enhanced tumor with a diameter of $82 \times 75 \mathrm{~mm}$ by axial (c) and coronal imaging (d, e) (arrows: anastomotic site; circle: tumor). 


\section{Case Reports in Gastroenterology}

\begin{tabular}{l|l}
\hline Case Rep Gastroenterol 2020;14:197-205 \\
\hline DOI: 10.1159/000506926 & $\begin{array}{l}\text { ○ 2020 The Author(s). Published by S. Karger AG, Basel } \\
\text { www.karger.com/crg }\end{array}$ \\
\hline
\end{tabular}

Koyama et al.: Desmoid-Type Fibromatosis of the Mesentery of the Small Intestine
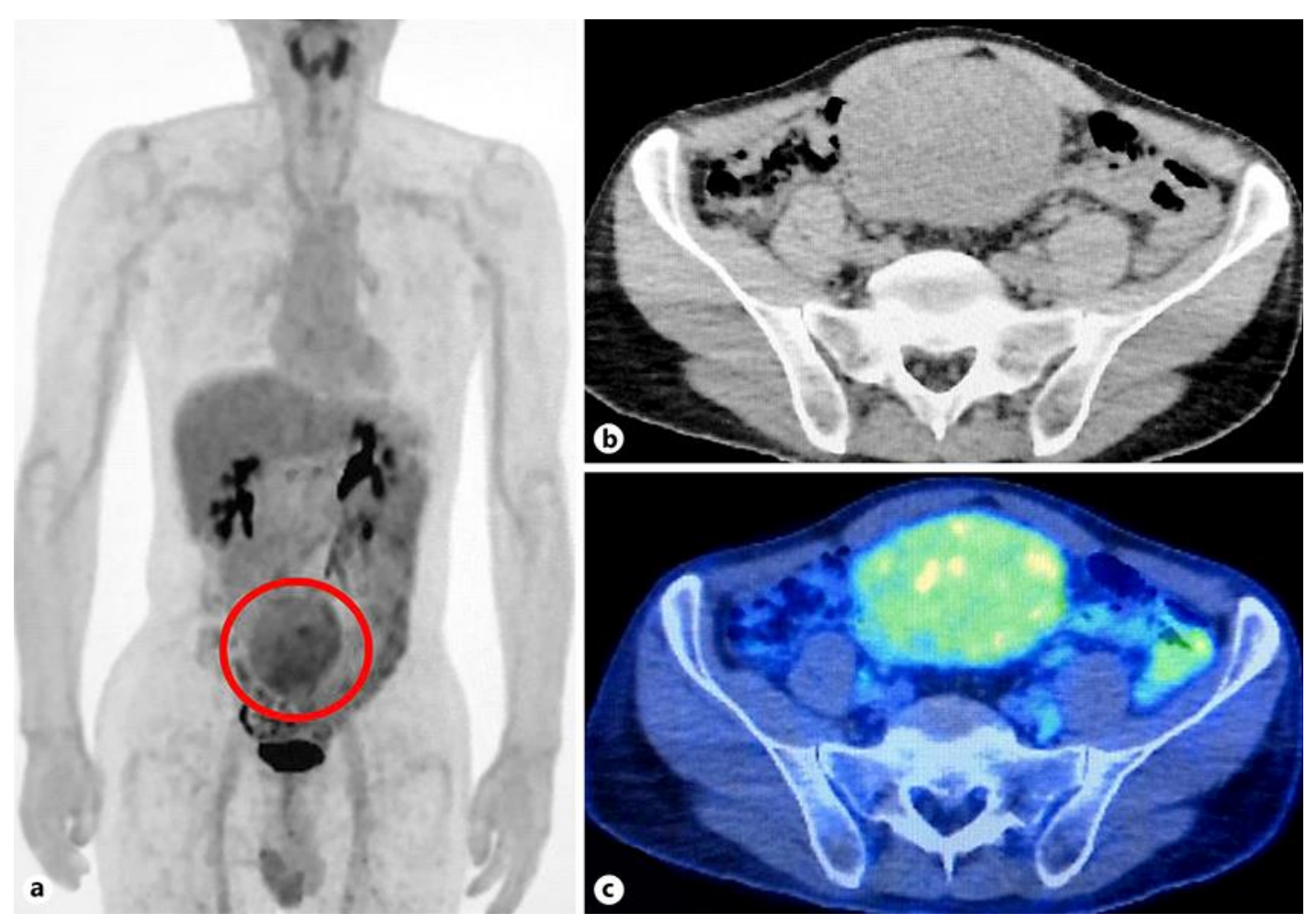

Fig. 2. Positron emission tomography (PET) images. The tumor (circle) showed a heterogeneously enhanced uptake on the lesion $\left(\mathrm{SUV}_{\max }=4.40\right)$ in the pelvis. No significant findings indicating metastasis or any other lesions were observed. a Whole body scan. b, c Axial images. 

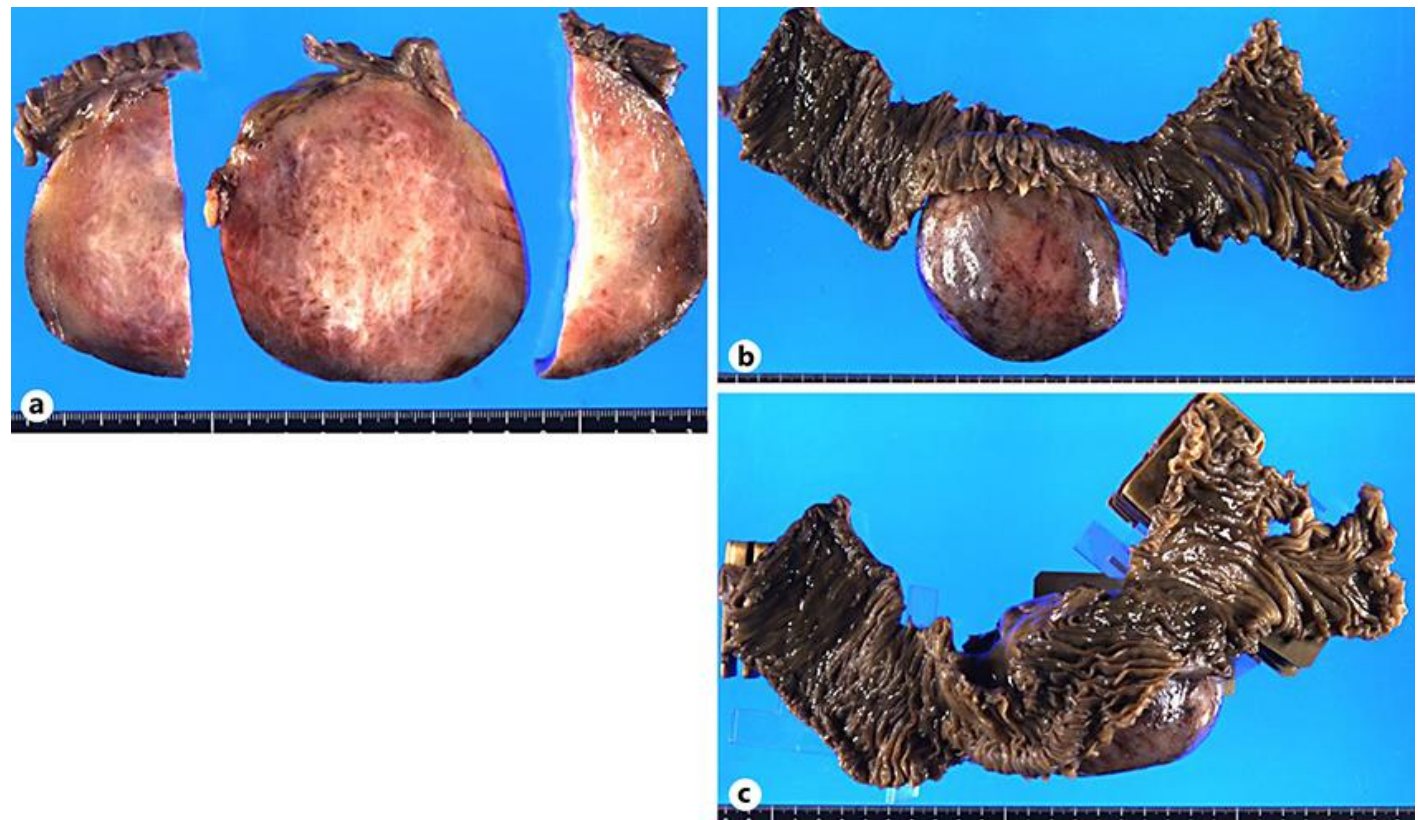

Fig. 3. Macroscopic findings in the resected specimen. a The resected specimen was a solid lesion with no necrosis or bleeding, measuring $10 \times 9 \times 8 \mathrm{~cm}$. b, c No exposure to the mucosa of the adjacent small intestine was observed, indicating its origin in the mesentery of the small intestine. 


\section{Case Reports in Gastroenterology}
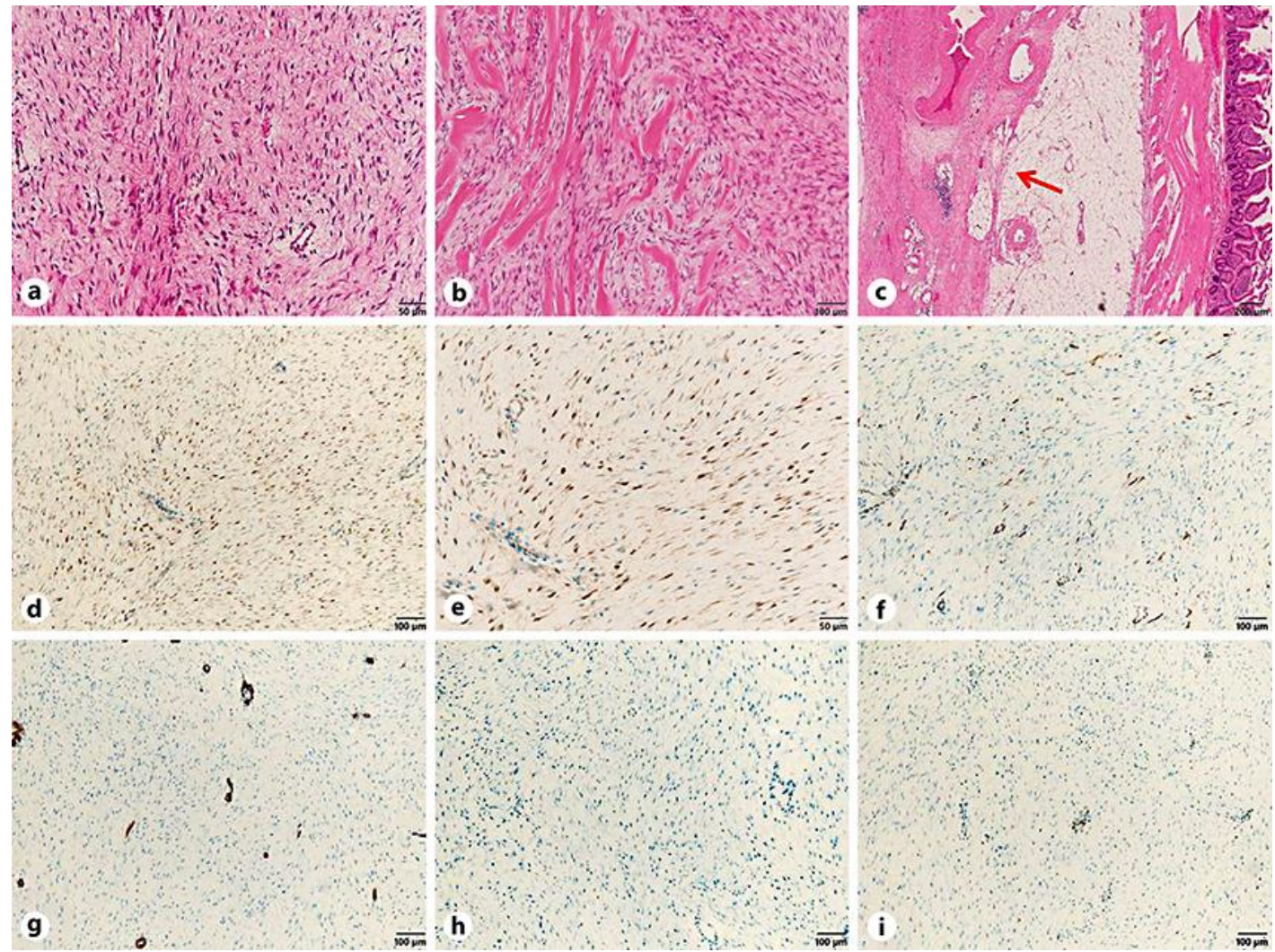

Fig. 4. Histopathology of the resected specimen. a, b Spindle-shaped cells resembling fibroblasts or myofibroblasts proliferated sparsely with intervening collagen fibers. c Invasive proliferation into the surrounding fat tissue was observed in the marginal area of the tumor (arrow). There was no continuity between the tumor (on the left side) and the wall of the small intestine (on the right side). $\mathbf{d}-\mathbf{i}$ The immunohistochemistry results showed positivity for nuclear accumulation of $\beta$-catenin (d, e), and negativity for $\alpha$ smooth muscle actin (f), CD34 (g), desmin (h), and c-kit (i). 